\title{
O VIÉS ECONÔMICO DE UM PAÍS COM HERANÇAS ESCRAVAGISTAS: A EMPREGABILIDADE DO NEGRO NO BRASIL ${ }^{1}$
}

doi> 10.33726/akdpapers2447-7656v9a62020p53-69

SILVA, Jakceli Costa da ${ }^{2}$

PESSOA, Marcelo ${ }^{3}$ - iD https://orcid.org/0000-0002-9193-4604

RESUMO: A análise da inserção do negro no mercado de trabalho é bastante complexa e se faz mais evidente pelo vislumbre histórico de fatos migratórios associados ao negro escravizado e trazido às colônias europeias, a partir do Século XVI. Justifica nosso estudo, o dado de que o desejo das equidades raciais no Brasil, ao mesmo tempo em que é causa negra, influencia diretamente toda a população econômica ativa (AYERBE, 2002). Por objetivo geral, esta pesquisa investiga a ideia de que a diplomacia brasileira pode ter tido papel determinante nos fatores econômicos relacionados ao negro brasileiro escravizado. Especificamente, espera-se compreender como os diplomatas podem ter atuado na transmutação das assimetrias históricas, particularmente às ligadas à libertação do negro brasileiro. Como resultado parcial, pode-se notar que o nosso país, desde 0 seu descobrimento e exploração colonial, passou por períodos de transformações, cujas potências socioculturais ainda não foram suficientes para promover a quebra da hegemonia branca em todos os segmentos sociais.

PALAVRAS-CHAVE: Inclusão social, negritude, escravidão moderna

ABSTRACT: The analysis of the insertion of blacks in the labor market is quite complex and is made more evident by the historical glimpse of migratory facts associated with black enslaved and brought to European colonies from the 16th century. Our study justifies the fact that the desire for racial equity in Brazil while being a black cause directly influences the entire active economic population (AYERBE, 2002). Overall, this research investigates the idea that Brazilian diplomacy may have played a determining role in the economic factors related to the enslaved Brazilian black. Specifically, we hope to understand how diplomats may have acted in the transmutation of historical asymmetries, particularly those linked to the liberation of the Brazilian Black. As a partial result, it can be noted that our country, since its discovery and colonial exploitation, has undergone periods of transformation, whose sociocultural powers have not yet been sufficient to promote the breakdown of white hegemony in all social segments.

KEYWORDS: Social Inclusion, blackness, modern slavery

\footnotetext{
${ }^{1}$ Texto produto de Trabalho de Conclusão de Curso, do Bacharelado em Administração, UEMG / Unidade Frutal, defendido e revisado por pares, no final de 2019.

${ }^{2}$ Graduada do Curso de Administração pela UEMG - Unidade Frutal. jakcelicosta@gmail.com

${ }^{3}$ Doutor em Letras pela Universidade de Londrina. Orientador e Docente na UEMG - Unidade Frutal.
} 


\section{INTRODUÇÃO}

O Brasil é composto de várias etnias e raças: indígenas, amarelos, brancos, pretos e pardos. Nesta pesquisa, abordaremos com maior ênfase os afrodescendentes e suas peculiaridades nas relações diplomáticas e mercantis feitas no cenário socioeconômico brasileiro, trazendo uma breve abordagem dos fatos históricos que decorreram desde a chegada do negro ao Brasil até os dias atuais, bem como qual é a colaboração dele na evolução das relações trabalhistas de alto escalão governamental ocorridas no país.

A escravidão negra no Brasil foi grandemente responsável pela sustentação das lavouras no período chamado de sistema colonial. Assim, a servidão ajuda a formatar o momento em que as atividades realizadas nas lavouras eram todas dependentes do trabalho forçado e sem remuneração.

Por meio dele, os colonizadores transportavam milhares de negros em navios conhecidos por "Navios Negreiros". Dentre inúmeras condições humilhantes e degradantes, nessa viagem, esses homens sofriam maus tratos, violência de toda ordem, alimentação precária e ficavam submissos a várias doenças e epidemias.

No século XVIII, a monarquia brasileira começa uma grande revolução de pensamentos sobre as ideias iluministas de liberdade, igualdade e fraternidade, valores que contaminaram toda a sociedade. Então, sob o clamor destes bastiões, foram criadas duas Leis anteriores à Abolição da Escravidão: a "Lei do Ventre Livre" e a "Lei dos Sexagenários", tornando algumas faixas etárias livres da escravidão.

A "Lei do Ventre Livre", conhecida popularmente como "Lei do Rio Branco", foi promulgada em 28 de setembro de 1871, e rezava que todos os filhos de escravas, nascidos a partir da promulgação da Lei, seriam considerados livres. A "Lei do Ventre Livre", formulada pelo Barão do Rio Branco, libertava os filhos de escravos nascidos após a sua homologação.

Entretanto, ficou estabelecido que o dono da terra cuidaria da criança até que completasse seus oito anos de idade e, em seguida, poderia transferi-la ao governo e ser indenizado ou usufruir dos trabalhos da criança até seus 21 anos e libertá-la, sem nenhuma compensação financeira, desprendendo os senhores de obrigações. 
Já, a "Lei dos Sexagenários", promulgada em 28 de setembro de 1885, tornava livre escravos com mais de sessenta anos, prevendo-se, nesses casos, o pagamento de indenizações aos mesmos.

E, em 13 de maio de 1888, proclama-se a "Lei Áurea", que aboliu a escravidão no Brasil, selando o fim do ciclo da escravidão explícita. A "Lei dos Sexagenários" libertava os escravos com mais de 65 anos, e também desonerava os senhores das terras de qualquer obrigação de sustentar esses indivíduos. Em contrapartida, aos 60 anos de idade, eles, os negros, seriam dados como "libertos" e, para conseguir a alforria, trabalhariam mais cinco anos gratuitamente para seus donos, configurando uma indenização.

Segundo Silveira (2008), o Brasil atualmente (em 2019, o IBGE já acena para um volume que ultrapassou os 210 milhões) é composto de 208,5 milhões de pessoas e a previsão é que, até o ano de 2047, este número chegue a 233 milhões, sendo que mais da metade da população no país é formada por remanescentes da raça negra (somados aqui o número de pessoas que auto se declaram negras e/ou pardas).

É neste sentido, então, que, neste trabalho, também se debruça na ponderação sobre a participação efetiva da população negra no mercado de trabalho, aferindo os cargos (de baixo, médio e altos escalões) ocupados e destinados para essa parcela da população e os indicadores que originam a falta de desenvolvimento profissional nesse segmento étnico.

A abolição da escravidão será tratada num tópico à parte, fazendo-se uma breve discussão dos fatos históricos que se deram para a concretização da liberdade dos escravos negros, configurando-se, assim, a Lei Áurea.

Noutro ponto, destacaremos a origem da Diplomacia no Brasil, buscando nos registros históricos as vantagens obtidas pelos governantes brasileiros, donde relataremos a carência de integrantes negros nos cargos diplomatas e os obstáculos que se apresentam para quem almeja tais cargos e a relação da educação nacional com essa precariedade. 


\section{O TRABALHO E O RETRATO SOCIAL DA PROPRIEDADE E DOS AFRODESCENDENTES NO BRASIL}

O Brasil, no período pré-colonial, era uma terra com tantas riquezas que despertava o desejo e a vontade de enriquecimento que levavam os europeus a viajarem, colocarem suas vidas em risco por longas jornadas feitas em barcos sem segurança, tomando rumos ignorados.

A propriedade legal de terras da Colônia era baseada na propriedade rural, que se sustentava na mão de obra escrava e na produção de produtos que suportavam o clima quente e úmido. O tráfico negreiro, nesse sistema, era praticado da seguinte maneira: os traficantes capturavam os negros nas diversas colônias portuguesas da África, os transportavam pelos oceanos e os vendiam aos interessados oceano afora:

A mortandade dos negros, porém, pelo menos no século XIX, quando temos elementos para avaliar com segurança, não parece ter chegado aos índices aterradores com que a dramatizaram alguns escritores. Calógeras chegou a afirmar que "a percentagem de mortalidade ascendia regularmente a $30 \%$ nas cargas vivas". Fosse pela dispensa de maiores cuidados na travessia, fosse por uma prolongada experiência na exploração de tal comércio, o certo é que no início do século XIX as cifras são relativamente muito mais baixas do que as fazem supor alguns depoimentos (FILHO, 1946, p. 36).

Após a captura dos negros, os traficantes acorrentavam e marcavam com ferro em brasa os africanos, os quais eram violentamente conduzidos em navios negreiros. Nesse transporte, a precariedade era tão grande que, em média, $30 \%$ dos negros morriam durante a viagem. Os africanos que resistiam ao percurso chegavam ao porto brasileiro e eram vendidos em leilões. Logo em seguida, já eram escravizados e encaminhados para a realização de trabalhos na plantação de cana-de-açúcar, de algodão, no cultivo do café, na mineração, no artesanato.

As regiões brasileiras de maior lucratividade do tráfico foram as do Estado da Bahia e do Estado de Pernambuco, territórios onde os engenhos de açúcar mais prosperaram. O excesso de trabalho e as más condições de vida oferecida pelos senhores da terra reduzia e deteriorava rapidamente a saúde do escravo, fazendo com que a sobrevida da mão de obra negra se reduzisse rapidamente, circunstância em que se criava a necessidade de reposição, retroalimentando o vicioso círculo da escravidão.

Os tratamentos aos negros eram comparados aos dados aos animais. A alimentação era feita com o que sobrava da comida dos patrões, sendo colocada em 
cochos que serviam de alimentação aos bovinos, ou servidos na terra fria, dependendo do comportamento dos escravos, condição que podia determinar também a oferta de comidas velhas, causando intoxicação estomacal e distúrbios digestivos aos trabalhadores.

Naquela época, os fatos ocorridos nas fazendas eram escondidos e pouco se sabia dos sofrimentos e da violência imposta ao sujeito negro. Por muitos, os negros não eram tratados e nem vistos como um cidadão normal, mas, sim, como párias sociais.

As violações que os colonizadores praticavam contra o negro o rebaixavam ao nível do subumano, e a sociedade aceitava silente ou simplesmente não se impunha contra esse tratamento de desigualdade e, não querendo ir contra os senhores mais ricos que comandavam as colônias, indiretamente legitimavam socioculturalmente o rito da escravidão humana.

É possível fazermos uma ressalva. Vale lembrar que existiram, no período escravagista, relações socialmente possíveis entre escravos e brancos. Segundo Holanda (1995), em alguns contextos, o escravo não era considerado apenas como um instrumento econômico gerador de rendas, pois há registros de algumas tratativas trabalhistas, de proteção e de solidariedade entre os escravos e os proprietários de terra.

Apesar disso, as comunidades negras eram resistentes e lutavam contra a opressão, a violência, a humilhação a que eram submetidos. Registram-se, nesse tocante, a ocorrência de revoltas, fugas, assassinatos de feitores e de senhores: estas, dentre outras, foram parte das medidas utilizadas pelos escravos para lutar contra os abusos que aconteciam.

\section{A CRISE DO SISTEMA COLONIAL BRASILEIRO E AS CONSEQUÊNCIAS SOCIOECONÔMICAS: A ABOLIÇÃO DA ESCRAVATURA}

No final do século XVIII, dá-se a explosão de diversas revoltas populares que colocaram o sistema colonial em xeque, iniciando uma grande crise social, política e econômica. Um destes estopins da crise colonial foi a Conjuração Baiana.

Ela ocorreu no ano de 1798, e teve por ideal minimizar as injustiças sociais e raciais que oprimiam o povo. À época, suas principais aspirações eram: acabar com o domínio português e tornar o país uma República Democrática; abolir a escravidão do negro; aumentar o salário dos soldados; abrir negociações econômicas com outras 
nações e melhorar as condições de vida da sociedade. Seus principais representantes eram das camadas sociais mais humildes: alfaiates, soldados, mulatos, negros livres e escravos inconformados com tantas desigualdades, fome e miséria.

Entretanto, no ano de 1799, o governo colonial extinguiu esta revolução, a partir do assassinato de dois alfaiates e de dois soldados que foram enforcados e esquartejados. Além disso, aplicaram-se penas maiores a outros participantes do movimento, como medida exemplar e de opressão aos revoltosos.

Assim, a Abolição da escravatura, no Brasil, passou por várias etapas. A fase da "Lei Eusébio de Queirós", proibia o tráfico do negro e expulsava traficantes do país: a liberdade se tornou prevista e próxima. As reuniões abolicionistas e seus seguidores aumentaram rapidamente: parlamentares, artistas, militares e a imprensa aderiram ao movimento.

Segundo Holanda (1995, p. 76):

[...] Pode-se bem estimar a importância do golpe representado pela Lei Eusébio de Queirós, considerando que, naquele ano de 1845 , o total de negros importados fora de 19.363; em 1846, de 50.354; em 1847, de 56.172; em 1848, de 60 mil; em 1849, de 54 mil e em 1850, de 23 mil. A queda súbita que se assinala neste último ano resulta, aliás, não só da aprovação da aprovação da Lei Eusébio de Queirós, que é de 04 de setembro, como da intensificação das atividades britânicas de repressão ao tráfico.

O tráfico negreiro foi encerrado por determinação da "Lei Eusébio de Queirós", que extinguiu o tráfico do negro que ocorria no período do Segundo Reinado. Assim se fez, sob o ponto de vista econômico, para que houvesse a desvinculação do dinheiro usado na compra de escravos, introduzindo-se outras divisões econômicas, fazendo surgir novas formas de comércio que aumentaram os empregos aquecendo a economia interna.

Realizando uma rápida análise das Leis abolicionistas, percebemos certo descaso em suas entrelinhas. Por exemplo, aos 65 anos, os homens já seriam idosos e não gozariam mais de boa saúde ou mesmo de saúde alguma. E, devido aos maus tratos, poderiam não chegar aos 65 anos. Isto é, apesar dos "avanços" que precariamente representavam à época frente ao sistema colonial escravagista dominante, tais leis mais serviram para adiar, por mais um período de tempo, a tão esperada Abolição da escravatura. 
Foi indo nessa toada, entre vieses e reveses que, em 1888, após tantas lutas e resistências, que aconteceu a tão sonhada liberdade e, assim, encerrando-se a escravidão no Brasil. O principal marco da Abolição foi a Lei Áurea, proclamada pela Princesa Isabel, no dia 13 de maio de 1888.

As ideias abolicionistas tinham o ideal de acabar com as desigualdades sofridas pelos escravos e, em virtude deste ideal, não abordavam o fato de como seria a vida pós-escravidão, isto é, em que condições trabalhariam os negros libertos e como iriam sobreviver? Com a Abolição da escravidão, os negros se viram num outro grande obstáculo: sua inserção no mercado de trabalho. O negro era um homem livre, entretanto, aprisionado na escravidão.

Depois de várias medidas de transformação social e cultural, a Independência do Brasil não podia mais ser adiada e, antes mesmo da consolidação da Abolição em si, em 07 de setembro de 1822, é que se decreta a "Independência do Brasil":

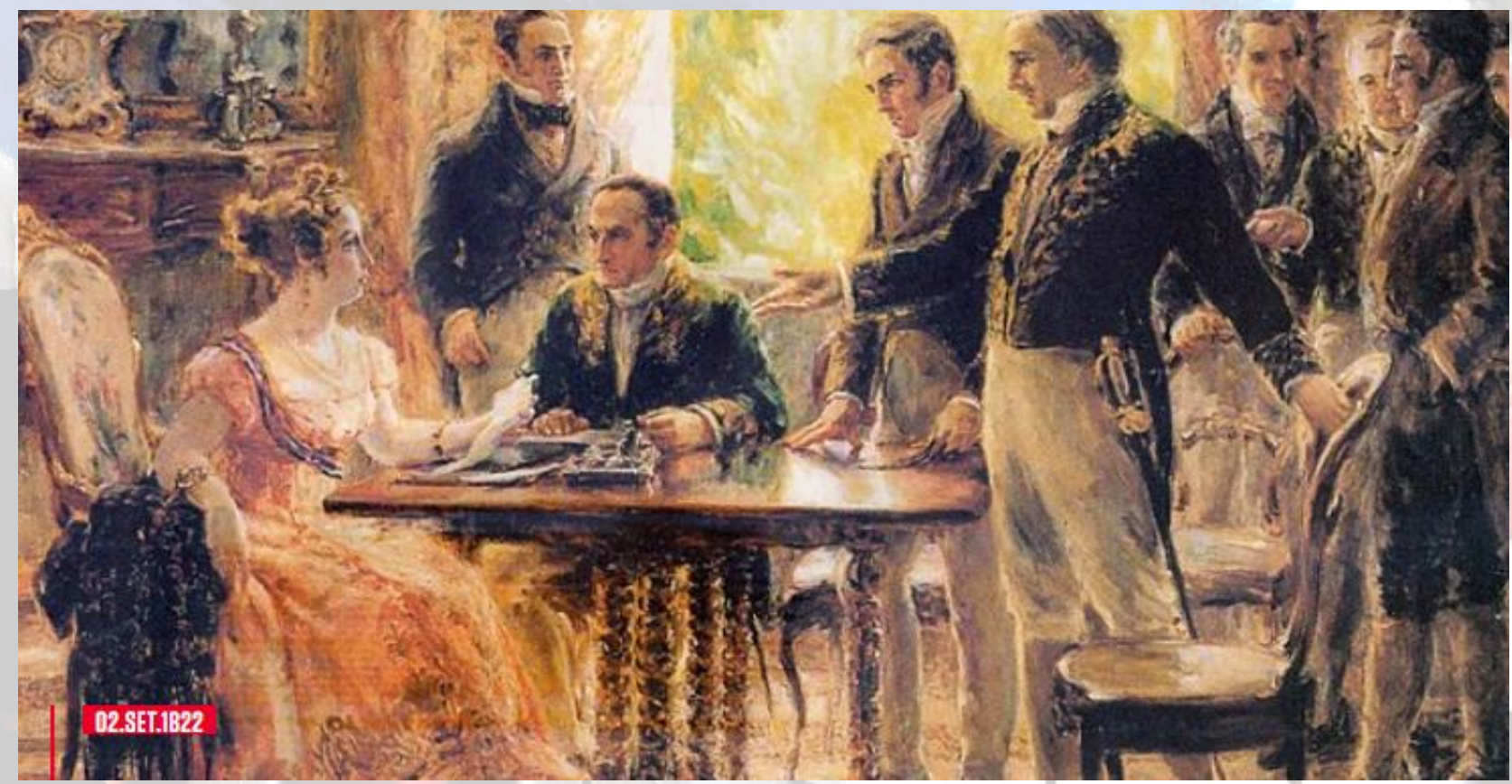

A Princesa Regente do Brasil, Maria Leopoldina, assinando o Decreto da Independência do Brasil Imagem em Domínio Público: https://br.historyplay.tv/

Um dos efeitos socioculturais mais intensos desse Decreto, foi o de que, com ela, a Independência, aumentaram o interesse pelos ideais de liberdade, pela força de expressão e pelos anseios por igualdade. 


\section{O TRÂNSITO SOCIOCULTURAL E ECONÔMICO DO HOMEM LIVRE PÓS- ABOLIÇÃO}

A dimensão deste entrave sociocultural e do homem livre pós-abolição é problemática, devido às dificuldades sociais, econômicas e políticas que afoitam a realidade da população brasileira pós-Independência e pós-Abolição, se configurando também em questões que as classes mais baixas ressentiram, face à falta de desenvolvimento profissional e sua marginalização:

Por sua vez, a ideologia do racismo afeta a prevalência de homicídios de negros, possivelmente, por dois canais. Indiretamente, a discriminação pela cor da pele pode afetar a demanda por trabalho de negros para postos mais qualificados, ou bloquear oportunidades de crescimento profissional. Pelo lado da oferta de trabalho, o racismo cria determinados estereótipos negativos que afetam a identidade e a autoestima das crianças e jovens negros, conforme discutido por Silvério (2002). Em última instância, o racismo reforçou, ao longo do tempo, o baixo status socioeconômico daquelas populações que foram largadas à sua própria sorte após a abolição, com baixa dotação de capital humano (CERQUEIRA; MOURA, 2013, p. 05).

Desenvolveram-se no país as favelas, conjunto de moradias populares que reúnem o conjunto das pessoas menos favorecidas e de classes sociais mais baixas. Elas vivem exclusas e sem base estrutural econômica nesses conjuntos habitacionais.

Para Oliveira, Moreira (2018, p. 36):

Um dos maiores fatores apontados no processo de violação de direitos e, pode-se afirmar, de forma generalizada à sociedade brasileira, diz respeito à violência. Sua multiplicidade de causas e consequências, aliada à complexidade da dinâmica objetiva e subjetiva da vida social, coloca a violência como um dos maiores desafios para a consolidação de um Estado de Direito. Isso porque se trata de uma dimensão que articula os âmbitos público e privado, muitas vezes de difícil apropriação, mas que, em função dos resultantes, exigirá respostas do Estado, tanto do ponto de vista coercitivo como de proteção e atendimento.

A sua marginalização é entendida no cenário de questões culturais, as diferenças e desigualdades existentes no país atingem mais os pretos, tais como são os pretos brasileiros que sofrem com a maior taxa de homicídios, feminicídios, taxas sobrelevadas pelo avanço da fome e da miséria:

Ser negro no Brasil é, pois com frequência, ser objeto de um olhar enviesado. A chamada boa sociedade parece considerar que há um lugar 
predeterminado, lá em baixo, para os negros e assim tranquilamente se comporta. Logo, tanto é incômodo haver permanecido na base da pirâmide social quanto haver "subido na vida" (SANTOS, 2000, s/p).

No cotidiano do negro brasileiro é bastante comum o racismo, que é levado até o mercado de trabalho. O posicionamento do negro no mercado de trabalho enfrenta dificuldades. O negro tem buscado o engajamento ao contexto produtivo iniciando seu processo economicamente ativo em diversas profissões e está buscando melhores qualificações, conhecimentos técnicos, aumentando suas competências.

Entretanto, o conceito que a sociedade construiu sobre a presença do negro na sociedade se transforma bem mais lentamente, aprisionando o homem contemporâneo ao costume da inferioridade do período escravagista.

\section{A MACROECONOMIA E SUAS RESPECTIVAS PULVERIZAÇÕES SOCIOECONÔMICAS}

A macroeconomia foi um termo criado após a Primeira Guerra Mundial, com as dificuldades econômicas causadas pela guerra e os países que saíram perdedores e desolados pelos altos níveis de desemprego. A queda de rendimento dos seus PIB' s, a desaceleração de seus parques produtivos, os preços das ações em declínio, constituíram eventos que levaram muitos economistas e pensadores a rediscutirem as políticas e os métodos para que esses países pudessem se reerguer.

Para o cálculo do PIB, conforme dados do IBGE (2019), são utilizados diversos indicadores sobre o consumo e o modo de viver da população. Esses indicadores são feitos pelo IBGE e também por outros órgãos: Balanço de Pagamentos (Banco Central); Declaração de Informações Econômico-Fiscais da Pessoa Jurídica - DIPJ (Secretaria da Receita Federal); Índice de Preços ao Produtor Amplo - IPA (FGV); Índice Nacional de Preços ao Consumidor Amplo - IPCA (IBGE); Produção Agrícola Municipal - PAM (IBGE); Pesquisa Anual de Comércio - PAC (IBGE); Pesquisa Anual de Serviços - PAS (IBGE); Pesquisa de Orçamentos Familiares - POF (IBGE); Pesquisa Industrial Anual Empresa - PIA - Empresa (IBGE); Pesquisa Industrial Mensal - Produção Física - PIM - PF (IBGE); Pesquisa Mensal de Comércio - PMC (IBGE); e, Pesquisa Mensal de Serviços - PMS (IBGE).

Com a crise de 1929, os Estados Unidos sentiram um efeito em certa medida oposto ao contexto global. Na sua economia havia uma superprodução, porém, a falta 
de demanda por seus produtos forçou as empresas a demitirem seus funcionários. Com isso, os americanos aumentaram seus níveis de desemprego, forjando um declínio rápido de todo o crescimento econômico conseguido no pós-guerra, fazendo o norteamericanos se juntarem, às avessas, ao cenário de baixa circulação de riquezas.

Os países perdedores, com o desenvolvimento macroeconômico, conseguiram a ascensão econômica, e com a diminuição da exportação dos produtos americanos, todas as empresas foram afetadas pelos dias difíceis. A Queda da Bolsa de Valores, em 1929, colocou os americanos num processo de reestruturação, pois diante deste momento, precisaram reinventar sua maneira de agir.

Os objetivos da macroeconomia são o crescimento econômico, o aumento na quantidade de oferta de emprego, a estabilização de preços e o equilíbrio nas transações externas. A macroeconomia, portanto, é um dos pilares do estudo de fenômenos econômicos como estes, posto que se baseia na análise e no desenvolvimento de fatores essenciais para o crescimento econômico de um país, ajudando na compreensão das relações que envolvem o intercâmbio de bens e serviços supranacionais.

A macroeconomia, em suma, aborda as variáveis econômicas como um todo, de forma agregada, parametrizada por períodos de recessão e de recuperação do nível do PIB (Produto Interno Bruto), vislumbrando o nível de preços, de taxas de emprego e desemprego, da balança de pagamentos, do nível de salários, da taxa de juros, da quantidade de moeda em circulação, da taxa de câmbio, do crescimento tecnológico e da distribuição de renda e do crescimento econômico.

\section{O DESEMPREGO, A INFLAÇÃO E O PIB: CANAIS PARA AS DESIGUALDADES SOCIAIS E INSUSTENTABILIDADE DA ECONOMIA NO CONTEXTO ECONÔMICO}

No final da década de 90 , os bancos estadunidenses começaram a emprestar dinheiro para todo o perfil de cliente, o que incluiu pessoas desempregadas e clientes inadimplentes. Para os clientes com pagamento em dia, esse crédito ficou conhecido por "subprime". Os bancos começaram a vender as CDOs (títulos de créditos hipotecários) para quem quisesse investir. As CDOs, por natureza, eram pacotes financeiros que configuravam as dívidas de grande risco, camufladas pela mistura de tais títulos às dívidas de baixo risco. 
Os países europeus foram os maiores compradores das CDOs, eles acreditavam que o negócio era excelente e que os ganhos futuros seriam maximizados, os investidores não tinham consciência de que os CDOs eram compostos de dívidas de clientes dos mais variados perfis. E, no dia 15 de setembro de 2008, inicia-se uma grande crise financeira devido a um dos bancos mais tradicionais dos Estados Unidos, 0 Lehman Brothers, ter ido a falência. A partir daí, os devedores não pagaram suas dívidas e os bancos e todos os países investidores começaram a ter sérios problemas de liquidez. Parte dos players da produção mundial reduziu a oferta de bens ou simplesmente desmobilizaram sua capacidade produtiva instalada, o que ocorreu inclusive no Brasil, fazendo explodir a taxa de desocupação.

É argumento de consenso, que o desemprego causa a desigualdade social e o cenário que se viu foi o de que uma grande quantidade de pessoas flertaram com a miséria. Nos últimos anos, com a ocorrência de crises macroeconômicas ocorridas no Brasil, o número de desempregados sofreu um aumento considerável. E, ainda em 2019, as formas de atuação das políticas adotadas pelo governo ainda não conseguiram retardar ou solucionar os graves problemas sociais. E, segundo o que foi divulgado pelo IBGE, certifica-se que aproximadamente 13 milhões de pessoas estejam desempregadas no país neste início de 2020.

As consequências mais evidentes destes tipos de contingências aparecem na elevação do nível da inflação e no aumento súbito do preço dos bens e serviços da economia. Em contrapartida, os salários recebidos pela população não conseguem acompanhar o crescimento paralelo dos preços e também a natural desvalorização do trabalho. Neste contexto, as empresas mantenedoras do crescimento econômico procuram ser mais competitivas ante as empresas estrangeiras investindo em inovação tecnológica, se desvencilhando do emprego de mão de obra humana, sujeitando a espécie sapiens a um novo ciclo de sujeições e privações: a escravidão moderna.

A macroeconomia, como se vê, articula em si, situações conflitantes, em que os seus objetivos principais de expansão econômica podem causar desequilíbrios sociais e comerciais frente à busca de crescimento econômico, levando a tomada de decisões governamentais às vezes controversas, medidas que podem ser de recessão no crescimento econômico para manter a economia do país estável ou mesmo de extinção de postos de trabalho, contribuindo para aumentar o sobrepeso social nas camadas de população mais vulneráveis aos sintomas econômicos. 


\section{DIPLOMATAS E SUAS CARREIRAS NO AVANÇO DE POLÍticAS GOVERNAMENTAIS}

Segundo o Itamaraty, os diplomatas deverão realizar funções voltadas tanto para o cunho econômico quanto para o social. Assim, é comum uma pauta de diálogo que englobe numa mesma rodada de negociações, temas sobre os direitos humanos, recursos elétricos, segurança pública, educação.

O cargo de diplomata exige que seus ocupantes negociem e mantenham relações comerciais e cordiais com os 194 países com os quais o Brasil se relaciona e com todos os órgãos internacionais mundiais do qual fazemos parte. Para o ingresso na carreira de diplomata é necessário ser aprovado em um concurso público realizado anualmente pelo Instituto Rio Branco (organismo público que homenageia em seu nome, um de seus grandes diplomatas, o Barão do Rio Branco, o mesmo que também, noutro momento da história brasileira, formulou a Lei do Sexagenário).

Esse Instituto foi fundado em homenagem ao Barão de Mauá e é um órgão do Itamaraty, este órgão é formado por três carreiras, sendo elas a de Diplomata, a de Oficial de Chancelaria e a de Assistente de Chancelaria. Em 2015, esse quadro era composto por 1565 Diplomatas, 839 Oficiais de Chancelaria, 574 Assistentes de Chancelaria e por 441 servidores públicos formados e concursados de outras áreas que atuam como apoio.

Segundo o Ministério das relações exteriores (2016), o Programa de Ação Afirmativa do Instituto Rio Branco, oferece uma Bolsa Prêmio de Vocação para a Diplomacia. Neste sentido, o Itamaraty investiu mais de $\mathrm{R} \$ 15$ milhões de reais nesse programa, aumentando a heterogeneidade das relações externas. Nesse programa ele está associado à outras instituições públicas, tais como o Ministério da Tecnologia, da Ciência, Inovações e Comunicações, o CNPq, a Fundação Palmares, a SEPPIR ${ }^{4}$, vinculada ao Ministério da Família, da Mulher e dos Direitos Humanos.

O programa foi efetivado em 2002, visando justamente a diminuir as diferenças raciais e mitigar as dificuldades de ingresso dos negros em carreiras diplomáticas. Este programa tem, em sua finalidade, conceder bolsas preparatórias que possam ofertar a mesma oportunidade de ingresso na carreira diplomata a pessoa autodeclarada negra.

Conforme Soares (2000, p. 25):

\footnotetext{
${ }^{4}$ Órgão do poder executivo do Brasil, sua finalidade é promover a igualdade nos grupos sociais e étnicos afetados pela discriminação (Secretaria de Políticas de Promoção da Igualdade Social).
} 
Em termos de políticas públicas, esses resultados apontam para a possibilidade de políticas de ação afirmativa (nas linhas de políticas de quotas) para negros serem úteis no combate à discriminação. Se a sociedade está restringindo o acesso dos negros à boa educação ou aos bons postos de trabalho, então cabe ao poder público garantir esse acesso, principalmente em termos educacionais.

O processo seletivo do Programa de Ação Afirmativa se dá em duas etapas, a primeira, de modo eliminatório e classificatório, avaliará conhecimentos e habilidades dos candidatos, realizando-se uma prova objetiva de conhecimentos gerais nas disciplinas de língua portuguesa e inglesa, em História do Brasil e noções de política internacional, na segunda etapa será realizada a averiguação da documentação concedida pelo candidato e uma entrevista técnica à Comissão Interministerial.

Segundo o Anuário do Instituto Rio Branco, até o ano de 2015, foram concedidas em torno de 630 bolsas para 375 bolsistas, sendo que 26 bolsistas foram aprovados e que entre os anos de 2002 e 2012, ao menos um candidato negro tenha se tornado Diplomata. Em 2005, infelizmente não houveram aprovados, no ano de 2015, o programa de incentivo conseguiu a aprovação de cinco bolsistas negros. Mesmo diante do fato exposto se fizermos um levantamento dos atuantes negros nos cargos de diplomatas, vamos nos deparar com uma enorme discrepância.

Políticas públicas, tais como a política de ação afirmativa, têm o objetivo de diminuir as diferenças econômicas e a discriminação, concedendo aos contingentes populacionais vulneráveis, como os remanescentes compostos por negros, pardos, mulatos, possibilidades de competição de igual para igual dentro de um mercado de trabalho altamente seletivo.

\section{A DIPLOMACIA NO BRASIL E OS ÍNDICES SOBRE A RELAÇÃO ENTRE A ESCRAVIDÃO E OS NEGROS ECONOMICAMENTE ATIVOS}

Para o IBGE, os negros estão procurando por melhores qualificações para competirem no mercado de trabalho. O número de afrodescendentes que cursam o ensino superior nas universidades públicas e privadas aumenta, devido a projetos e "novas Leis abolicionistas" feitas pelo governo federal. Mas, mesmo diante dessa evolução, ainda é exorbitante o grande número de negros desempregados no país, e isso demonstra as disparidades que o país enfrenta, ainda que fora de momento de crise global, com a da queda da bolsa (1929), ou a dos títulos hipotecários (2008). 
Conforme Guimarães (apud FREYRE, 1950, p. 151):

No caso que nos interessa mais de perto aqui, a democracia "étnica" de que falava Freyre, em 1950, sem esconder certo cientificismo culturalista, transforma-se rapidamente em democracia racial tout court, em referência direta aos conflitos raciais que começam a rasgar o racismo legal dos Estados Unidos. Ao contrário de lá, pensavam scholars e militantes, já tínhamos um legado de democracia racial desde a Abolição. Para os movimentos negros, entretanto, a abolição não fora completa, pois não representara a integração econômica e social do negro à nova ordem capitalista: tanto para a geração dos 30 (a Frente Negra Brasileira), quanto para a geração dos 50 (o TEN), seria necessária uma segunda Abolição.

Conforme informações obtidas por pesquisas realizadas pelos órgãos governamentais, a população negra brasileira ainda encara praticamente os mesmo obstáculos econômicos e sociais experienciados no período pós-Abolição.

Ao lado dessa perspectiva história, acrescentou-se a violência urbana. Esta é uma causa geradora de vários óbitos de jovens negros, fazendo com que boa parte deles não chegue sequer a cursar o nível médio de ensino. As instituições escolares públicas são carentes de infraestrutura, a sociedade branca também é dependente desse mesmo sistema educacional precário.

O Brasil passa, enfim, por um momento crítico em seu perfil socioeconômico, os países com os quais mantemos relações comerciais impõem muitas regras e empecilhos evolutivos aos países em desenvolvimento. E, para que esses impedimentos e objeções sejam amenizados, o governo precisa contar com a classe diplomática. Em cargos de poderes no alto escalão governamental, conseguimos precisar a exiguidade dos negros, posto que apenas uma dessas funções seja ocupada por um afrodescendente.

\section{CONSIDERAÇÕES FINAIS}

Nos anos 2000, notamos que o país modificou sua planta estrutural, justamente visando embalar o grande desenvolvimento econômico que se desenhava no cenário internacional. Para isto, procurou-se, por aqui, desenvolver programas e medidas que tentaram diminuir as desigualdades existentes e historicamente ocorridas no país.

Por sua vez, o governo, atraído que estava pela expansão econômica internacional, fez promessas de igualdade social para crescer frente à opinião pública e ao mercado estrangeiro. As classes mais sofridas foram, entretanto, de um modo geral, 
esquecidas por este mesmo governo, no tocante às medidas sociais oferecidas. Essas medidas não satisfizeram às necessidades de que o povo brasileiro carecia e ainda carece: as situações de precariedade socioeconômica ainda continuam.

Algumas medidas de fomento ao desenvolvimento não chegam às pessoas que realmente precisam. A julgarmos pelo nível e teor das Leis aprovadas pelo Congresso Nacional (que têm se preocupado mais com os interesses políticos e menos com as questões sociais), os cidadãos brasileiros que não possuem condições mínimas de vida, que não possuem saneamento básico, de água e de esgoto tratados, as crianças que não possuem ensino de qualidade, todos continuarão não tendo acesso a tais bens sociais.

O Brasil passa por uma fase de deficiência de medidas efetivas que englobem a população como um todo. Para que isto ocorra do modo como vem acontecendo, existem múltiplas justificativas.

Com as reformas trabalhistas recentes (particularmente as levadas a termo pelo final do Governo de Michel Temer - final do ano de 2018), os trabalhadores sentiram o impacto do aumento do tempo trabalhado para se aposentar e, para trabalhadores que nunca tiveram carteira assinada e não seguiram os regimes da CLT (Consolidação das Leis do Trabalho), esse tempo se torna relativamente mais longo, especialmente com a Reforma da Previdência, aprovada no primeiro ano do governo de Jair Bolsonaro.

O trabalhador socialmente mais vulnerável, dentre os quais destacamos o sujeito negro, às vezes, não consegue trabalhos com carteira assinada ou não contribui com o INSS (Instituto Nacional de Seguridade Social). Nisso, se veem ainda mais distantes da aposentadoria do que todos os demais empregados formais.

O crescimento do trabalho autônomo demonstra que o povo brasileiro está se engajando em outros modelos econômicos e que a economia está sendo moldada pelos próprios brasileiros, já que influenciados pela necessidade encontrada para sua sobrevivência.

O recente empoderamento dos negros, no início do século $\mathrm{XXI}$, trouxe, para o mercado de trabalho, a espada da batalha árdua por mais oportunidades, revelando a grande transição histórica que ainda e tardiamente acontece, envolvendo a mão de obra escrava para a mão de obra empoderada e qualificada.

A relação explícita entre a histórica escravidão e a inserção livre no mercado de trabalho pode ser trabalhada de forma relevante, ao propiciar o entendimento de tantas 
desigualdades sociais que perpassam os séculos e insistem em se manter ativas. A escravidão durou três séculos e, ainda, nos dias atuais, nos deparamos com seus resquícios, quando observamos a realidade e o retrato do negro brasileiro face aos diversos fatores herdados historicamente, tais como a repressão sociocultural e econômica que se prolonga por tanto tempo.

Em cargos de confiança ou do alto escalão do governo, é raro notarmos a presença de alguém negro. Cabe-nos a reflexão sobre quais seriam os motivos que explicam essa ausência de representantes negros, sendo que eles são a maioria da população, tanto no Brasil quanto em muitos outros países.

Os negros, em sua maioria, se deparam com a dificuldade de cursar o ensino superior e o acesso às especializações para o desempenho de cargos e funções qualificadas, grande parte dos negros estuda em escolas públicas e com estruturas frágeis de atendimento às necessidades dos alunos: a evasão escolar é bastante determinante para o insucesso escolar do negro. Assim, é fato que, para as famílias consideradas pobres, pode ser que o trabalho se torne mais importante que o conhecimento. 


\section{REFERÊNCIAS}

AYERBE, Luis Fernando. Estados Unidos e América Latina: a construção da Hegemonia. São Paulo: UNESP, 2002.

CERQUEIRA, Daniel R. C; MOURA, Rodrigo Leandro de. Vidas perdidas e racismo no Brasil. Instituto de pesquisa econômica aplicada - IPEA. Brasília: Nota técnica n. 10, p. 5, nov. 2013. Disponível em: http://www.geografia.seed.pr.gov.br/arquivos/File/noticias_2013/vidas_perdidas_racismo_brasil.p df. Acesso em: 05 dez. 2019.

FILHO, Luiz Viana. O negro na Bahia. São Paulo: Livraria José Olympio Editora, 1946.

GUIMARÃES, Antônio Sergio Alfredo. Democracia racial: o ideal, o pacto e o mito. Novos Estudos CEBRAP - USP. São Paulo, n. 61, p. 147-162, nov. 2001. Disponível em: http://novosestudos.uol.com.br/produto/edicao-61/. Acesso em 07 dez. 2019.

HOLANDA, Sergio Buarque de. Raízes do Brasil. $26^{\circ}$ ed. São Paulo: Companhia das Letras, 1995.

INSTITUTO BRASILEIRO DE GEOGRAFIA E ESTATÍSTICA - IBGE. Produto interno bruto PIB. 2019. Disponível em: https://www.ibge.gov.br/explica/pib.php. Acesso em: 20 nov. 2019.

MINISTÉRIO DAS RELAÇÕES EXTERIORES. Anuário do Instituto Rio Branco. Brasília: Instituto Rio Branco, 2016. Disponível em: http://www.institutoriobranco.itamaraty.gov.br/images/pdf/Anuarios/Anurio-20151.pdf. Acesso em: 20 out. 2019.

OLIVEIRA, Iris Maria de; MOREIRA, Maria Regina de Avila. O processo de ocupação das cidades: a segregação em Natal/RN a partir das condições de infraestrutura nas periferias. In: Desigualdade social e políticas sociais: estudos sobre expressões da questão social e políticas de enfrentamento a pobreza na cidade e no campo. Jundiaí, SP: Paco editorial, 2018. p. 22-50. ISBN 978-85-4620-850-0. Disponível em: https://pt.scribd.com/read/405793144/DesigualdadeSocial-e-Politicas-Sociais-Estudos-sobre-Expressoes-da-Questao-Social-e-Politicas-deEnfrentamento-a-Pobreza-na-Cidade\#. Acesso em: 08 dez. 2019.

SANTOS, Milton. Ser negro no Brasil hoje: ética enviesada da sociedade branca desvia enfrentamento do problema negro. Folha de São Paulo, p. 4, 07 maio. 2000. Disponível em: https://edisciplinas.usp.br/pluginfile.php/772221/mod_resource/content/1/Se.pdf. Acesso em: 01 nov. 2019.

SILVEIRA, Daniel. Brasil tem mais de 208,5 milhões de habitantes, segundo o IBGE, 2008. Disponível em https://g1.globo.com/economia/noticia/2018/08/29/brasil-tem-mais-de-208milhoes-de-habitantes-segundo-o-ibge.ghtml. Acesso em: 10 fev. 2018.

SOARES, Sergei Suarez Dilon. Perfil da discriminação no mercado de trabalho: homens negros, mulheres brancas e mulheres negras. Repositório do conhecimento. IPEA: Brasília, Texto para discussão $n^{\circ}$ 769, ISSN 1415-4765, p.25, nov. 2000. Disponível em: http://repositorio.ipea.gov.br/handle/11058/2295?mode=full. Acesso em: 20 out. 2019. 